\title{
WHY IS THE TAPHONOMIC CLOCK SUCH A POOR TIMEKEEPER?
}

FLESSA*, Karl W., HALLMAN, Diana P., Department of Geosciences, University of Arizona, Tucson, AZ 85721, U.S.A.; GOODFRIEND, Glenn A., Geophysical Laboratory, Carnegie Institution of Washington, 5251 Broad Branch Road N.W., Washington, D.C., 20015, U.S.A.; KOWALEWSKI, Michal, Department of Geosciences, University of Arizona, Tucson, AZ 85721, U.S.A.

In taphonomy, things should go from bad to worse. Soft parts decay, skeletons disarticulate, and hardparts break, abrade and discolor. Although it's often easy to distinguish hardparts that differ in age by tens of thousands of years or more, calibrating the taphonomic clock over shorter time intervals has proven to be a difficult task. Studies of radiocarbon-dated shells from the Gulf of California show that well-preserved hardparts are typically young, but that poorly-preserved remains can be either old or young. Such studies, however, often suffer from two problems: (1) composite measures of taphonomic condition that sum such different features as degrees of abrasion, bioerosion, and discoloration; and (2) small samples sizes because of the high cost of radiocarbon dating.

We examined the taphonomic condition and alloisoleucine/isoleucine ratio $(\mathrm{A} / \mathrm{I})$ of 142 shells of the bivalve mollusk Chione fluctifraga from the active and inactive shelly cheniers of the Colorado River delta, Baja California, Mexico. Chione fluctifraga is a shallow-burrowing bivalve that inhabits the sands and silts of the intertidal and shallow subtidal. After death, the shells are exhumed by waves and tidal currents and accumulate in intertidal and supratidal beach ridges. Each shell was scored as either good (1), fair (2) or poor (3) for each of six taphonomic features: bioerosion, encrustation, external color, internal color, fragmentation, and wear. A composite taphonomic score for each shell was calculated by adding the shell's individual scores.

We used each shell's $\mathrm{A} / \mathrm{I}$ value as a measure of its time-since-death. The A/I value is highly correlated with the shell's radiocarbon age: as much as $95 \%$ of the variation in $\mathrm{A} / \mathrm{I}$ values can be explained by the variation in radiocarbon ages. Shells ranged in age from modern to approximately 2,000 years. We calculated the rank correlation between taphonomic condition and $\mathrm{A} / \mathrm{I}$ value to evaluate the reliability of the taphonomic clock over this time interval.

Shells collected from below the surficial shell pavement have significantly $(p<$ 0.05) positive rank correlations between external color alteration and age, and fragmentation and age. $R^{2}$ values, however, never exceed 0.20 , showing that only a small proportion of the variation in taphonomic condition can be explained by the variation in time-since-death. The degree of bioerosion, internal color alteration, and wear were not significantly correlated with age. The degree of encrustation, however, is negatively correlated with shell age: encrustations apparently fall off with increasing time-sincedeath. In this instance at least, a shell's condition actually gets better with time

Taphonomic condition is an unreliable guide to a shell's time-since-death over this time period. Shells may be quickly buried beneath the surface, where the taphonomic clock runs slowly, or shells may be recycled to the surface, where the clock runs quickly. Each shell keeps its own time and the net result is a clock that doesn't work very well. 